\title{
EMPLOYEE MOTIVATION AND WORK PEFORMANCE IN ORGANIZATION
}

\author{
D.O.I - 10.51201/Jusst12617 \\ http://doi.org/10.51201/Jusst12617 \\ Dr. Veena I Bhavikatti \\ Assistant professor \\ Gurukul Degree College \\ Kalaburgi \\ Dr. Sony Hiremath \\ Karnataka State Akkamahadevi Women’s University \\ Vijayapura
}

\begin{abstract}
In the modern workplace, human resources occupy a prune position. The bricks of an institution are its people. The success of a good organization depends on two factors one is the efficiency of the staff and the other is the motivation given by their organization. Motivated employees are productive, happy, and committed. Professionals need to be given due importance by motivating them through rewards, incentives, and other positive approaches to enhance their morale. Motivated employees provide effective services to the patrons which in turn satisfies the organization's goal. They should be capable of organizing and providing information to the right person at right time.
\end{abstract}

Keywords: Employee, Performance, Motivation, organization, Human resource.

\section{Introduction}

Motivation is one of the most important factors affecting human behavior and performance. Hence, managers attach great importance to motivation in an organization. Likert (1961) has called motivation as the 'core of management' Rao (2000) opines that the key to motivation to structuring meaningful jobs, jobs that are challenging and rewarding, that provide increased opportunities for achievement, responsibility, growth, and recognition. Motivating employees can be a manager's biggest challenge. Employee motivation is the key to the overall effectiveness of an organization. Employee motivation describes an employee's intrinsic enthusiasm and drives, to accomplish work. Every employee is motivated about something $\mathrm{m}$ his or her life. Motivating employees about work is the combination fulfilling the employee's needs and expectations from work. Motivation causes goal oriented behavior. Motivation is necessary for 
work performance because if people do not feel inclined to engage themselves in work behavior, they will not put in the necessary effort to perform well. Motivation is an important factor that may affect an individual's performance. Hence, it is necessary for every superior to motivate his subordinates towards the right type of behavior. As individuals are the basic component of any organization, it is of prime importance to motivate them in all respects.

\section{Objectives}

Some of the objectives of the study are as follows;

1. To study the organizational factors influencing the work performance and employee motivation, job satisfaction, and contentment of staff.

2. To appraise human resource management, process, and systems existing in an organization such as staff pattern, rewards, and promotion policy.

3. To identify and analyze the job and work environment in the organization.

Employee Motivation and Work Performance in an Organization Like fuel is needed to run a vehicle, motivation is needed to drive action. Motivation to act or to perform comes on account of some trigger such as to cause objective, curiosity, faith, loyalty, etc. The motivation factor varies from person to person, time to time, and from situation to situation. Motives are cognitive variables. They prompt people to action. In earlier years, managers motivated workers to achieve higher productivity. In more recent times, managers have grown increasingly interested in finding ways to motivate and challenge workers to keep them from seeking more challenging opportunities elsewhere. The performance of an individual in an organization depends on a variety of factors besides motivation.

Role of Motivation: Motivation causes goal-oriented behavior. Motivation is necessary for work performance because if people do not feel inclined to engage themselves in work behavior, they will not put in the necessary effort to perform well. Motivation is an important factor that may affect an individual's performance. Hence, every superior must motivate his subordinates towards the right type of behavior. As individuals are the basic component of any organization, it is of prime importance to motivate them in all respects. Motivation plays a vital role in shaping the employee's development in an overall manner. The importance of motivation in an organization is as follows.

High-Performance Level Motivated employees give the higher performance as compared to other employees. Low Employee Turnover and Absenteeism When the employees are motivated they stay long in the organization and their absence is also minimal. Whenever there are high turnover and noncooperation from the employees, the organization will be 
affected badly which will reflect on the reputation of the organization. Acceptance of Organizational Changes technological development has brought tremendous changes in the organizational structure and an organization has to incorporate all those changes. Only a motivated employee can strive hard to accept, introduce and implement these changes keeping the organization on the right track of progress and success.

\section{Conceptual relationship between employees' motivation and organizational performance}

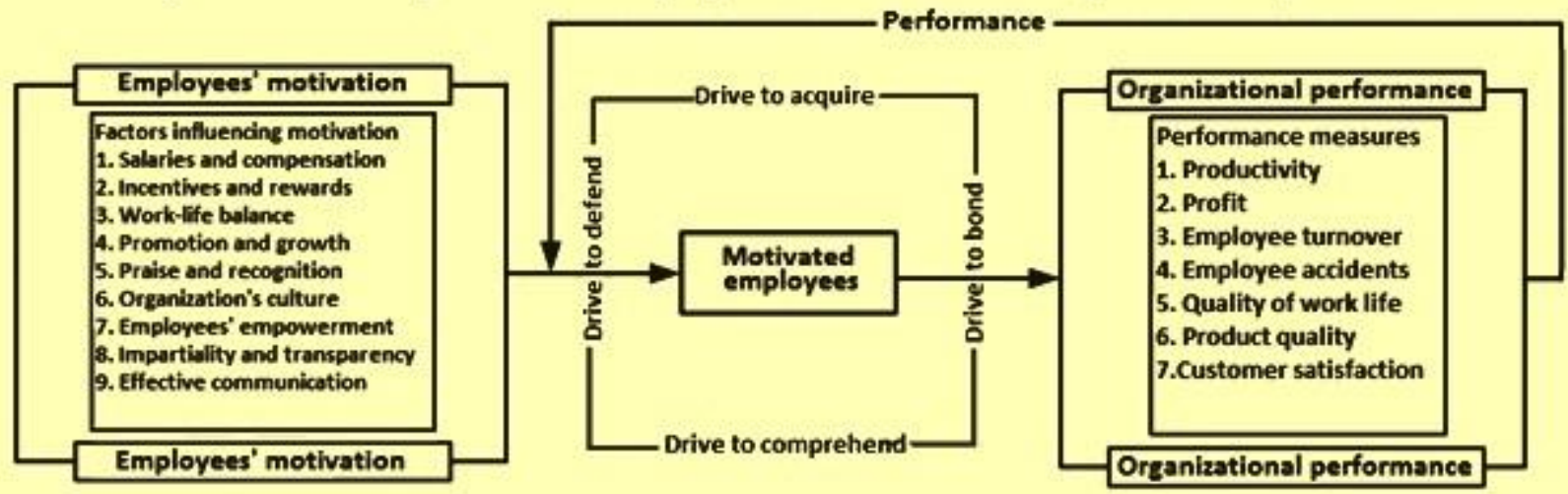

Employee Motivation As it is depicted in the figure, employee motivation describes an employee's intrinsic enthusiasm about and drives to accomplish work. Every employee is motivated about something in his or her life. Motivating employees about work is the combination of fulfilling the employee's needs and expectations from work and workplace factors that enable employee motivation - or not.

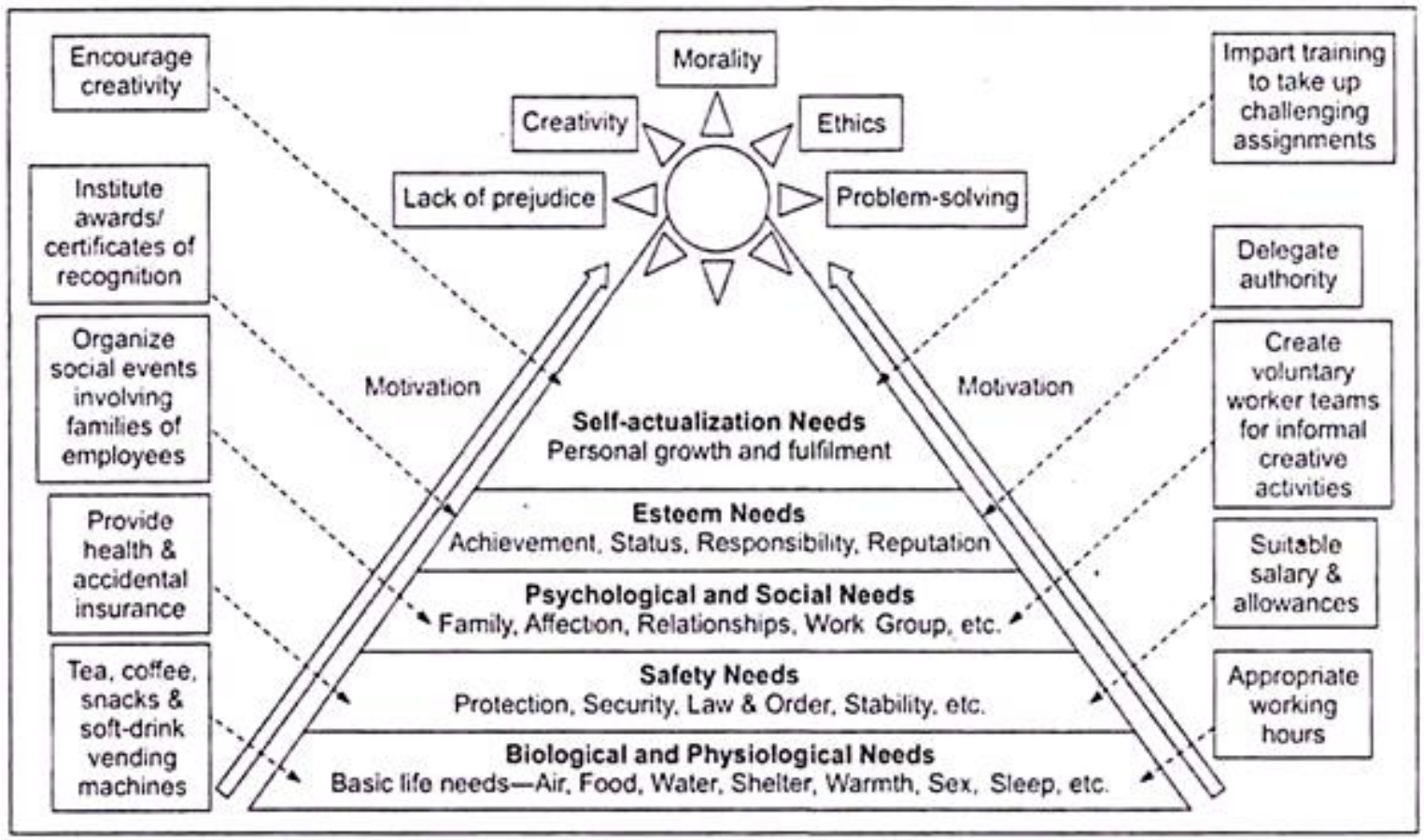

Figure 4.2 Maslow's Hierarchy of Needs Pyramid 


\section{MCGREGOR'S THEORY X \& Y}
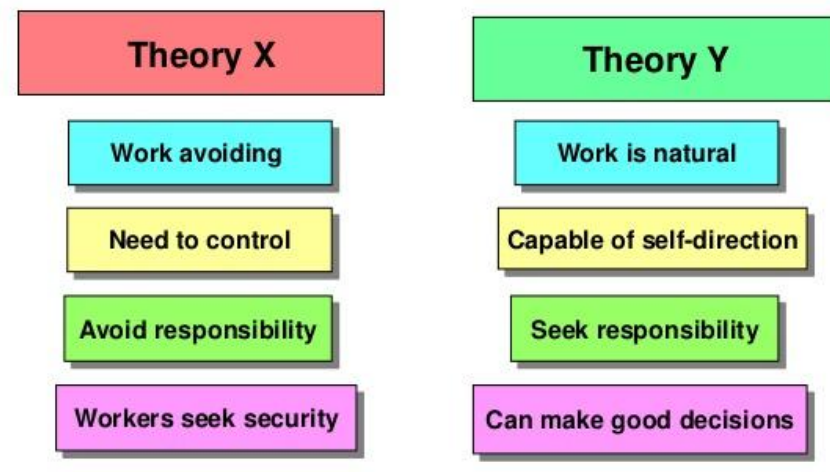

After investigating different motivational factors, we came that four intrinsic (such as: interesting work, job appreciation, job satisfaction, stress) and four extrinsic factors (job security, promotion $\&$ growth, good wages, recognition) will be consider for this study. These factors are taken on the basis of Maslow's Need theory, Alderfer ERG theory, Herzberg two factor theory, and Expectancy theory.

\section{Research Methodology}

Here adopted quantitative study to fulfill the research purpose. It is purely an empirical study that relies on primary data through the questionnaire as the source of data. It is purely an empirical study that relies on primary data through the questionnaire as the source of data.

\section{Research Design}

This is essentially a correlation research that applies quantitative approach and uses the survey method to collect data. It was used self-designed structured questionnaire to collect the data from the respondents. Employee's motivation and work performance is taken for the study.

Sample size: 100

Sample Approach: Convenience method.

\section{Hypothesis:}

H1: There is a significant relationship between motivation and employee performance

H0: There is no significant relationship between motivation and employee performance. 
For this hypothesis researcher has conducted Correlation Coffient analysis to understand the strong relationship between two variables. So it found that Employee motivation has positive relationship with employee performance and both the variables are dependent on each other. So, here we accept alternative hypothesis and reject null hypothesis.

\section{Findings:}

1. In the study $80 \%$ of the employees are satisfied with the support from HR department.

2. Based on the analysis $95 \%$ of the employees are motivated with financial incentives.

3. $91 \%$ of the incentives and other benefits will influence the work performance.

4. It is found that $82 \%$ of employees motivated to do extra mile at work.

5. It is observed that $60 \%$ of employees tell that management involve them in decision making which are connected to department.

\section{Conclusion}

Employee motivation is very important for a successful organization, so the organization should focus on it in order to stay competitive in the market and avoid some problems such as employee high turnover that will affect the business. Firstly, it can be concluded that it is surely potential to motivate employees to work well for an organization and that it is vital task for managers. It appear to be that there exist a self-rewarding circular correlation amongst the performance, satisfaction and motivation of an employee; an employee accomplish a high performance, hence inner satisfaction springs up and the employee is motivated to perform well in the future. It is said that a high performance can be attained when the organization renders certain job characteristics. Secondly, it is stated that employees can be intrinsically and extrinsically motivated at the same time to perform very well. Most of the jobs are both intrinsically and extrinsically motivated. Thus, effective motivational techniques should be practiced at the workplace. This study, we can conclude that different research gave rise to different results for the most influential intrinsic factors. Research shows that to intrinsically motivate employees, the organization needs to reach high on five job characteristics; skill variety, task identity, task importance, autonomy and feedback. On the other hand, to extrinsically motivate employees, the organization needs to reach high on commitment to supervisors and peers, salary and job security. It is significant that managers supply all job characteristics, since it will give way to high employee performance. 


\section{References}

1.Amabile T.M , 1993. Motivational synergy: toward new conceptualizations of intrinsic and extrinsic motivation in the workplace. Human resource management.

2.Armstrong, M., \& Baron, A. (1998). Performance management: the new realities. London' Institute of Personnel and Development.

3.Chhabra, T. N (2010). Principles and practice of management. Delhi* Dhanpat Rai and Company.

4.Choudhury, M. R. (2004). Human performance for organizational development. HRM Review, 8(2), 75-77.

5.Mamshankar, C. (2008). Performance Management System. HRM Review, January,2008,4145 . 